\title{
The impact of the Risks of the Input of Accounting Information Systems on Managerial Control, Accounting Control and Internal Control in Commercial Banks in Jordan
}

\author{
Mohammed AL-Sharairi ${ }^{1}$, Atallah Al-Hosban ${ }^{2}$ \& Hussam Thnaibat ${ }^{2}$ \\ ${ }^{1}$ Irbid National University, Jordan \\ ${ }^{2}$ Aqaba university of Technology, Jordan \\ Correspondence: Atallah Al-Hosban, Aqaba University of Technology, Jordan. E-mail: aalhosban@gmail.com
}

Received: December 15, 2017

Accepted: January 7, 2018

Online Published: January 15, 2018

doi:10.5539/ijbm.v13n2p96

URL: https://doi.org/10.5539/ijbm.v13n2p96

\begin{abstract}
The study aimed at determining the impact of the risks of the input of the accounting information systems on the accounting control, administrative control, and internal control. The questionnaire was used to obtain the study data. The study community consisted of internal auditors in commercial banks. Statistical methods were used such as: arithmetic mean, standard deviation, and Kronbach Alpha test. The most important results of the study: the impact of the risks of accounting information systems on administrative control and accounting control and internal control. One of the most important recommendations: the need to document all the data of the accounting system, and the need to train staff on how to reduce the risks of accounting information systems in general
\end{abstract}

Keywords: risk, accounting information system, managerial control, accounting control, commercial banks

\section{Introduction}

When planning a security program, the AIS technical manager should be aware of all the types of threats that may be encountered. Not every Navy AIS facility will be faced with each type of threat, especially if the facility is aboard ship. The impact of a given threat may depend on the geographical location of the AIS facility (earthquakes), the local environment, and potential value of property or data to a thief, or the perceived importance of the facility to activists and demonstrators or subversives. The AIS facility upper management should begin development of the security program with a risk analysis. A risk analysis, potential hazards that could threaten the performance, integrity, and normal operations of an AIS facility. Experience at various commands shows that a quantitative risk analysis produces the following benefits : Objectives of the security program relate directly to the missions of the command, Long-range planners receive guidance in applying security considerations to such things as site selection, building design, hardware configurations and procurements, software systems, and internal controls. This study is based on the use of two sources of information: the first source represents the use of the questionnaire for distribution to internal auditors in Jordanian commercial banks. The second source is the use of books, references and previous studies in order to enrich the theoretical framework of the study

\subsection{The study Problem}

This study attempts to answer the following question: "What is the effect or reflection of the risks of the inputs of the accounting systems on administrative control, accounting and internal control in commercial banks in Jordan?

The elements of the study problem are

1. What is the impact of the input of accounting information systems on administrative control?

2. What is the impact of the input of accounting information systems on accounting control?

3- What is the effect of the input of the accounting information systems on internal control? 


\subsection{Procedural Definitions}

- System: It is a comprehensive framework of a set of interconnected and related parts and elements that interact with each other to achieve specific objectives benefiting the beneficiaries. (Dahlama, 2008)

- Accounting system: It is a set of manual and computerized processes aimed at establishing accounting records, and then setting controls and methods to analyse and summarize them so as to facilitate their handling and utilization in decision making within the organization's environment (Roomney, 2015).

- Control Risks It is the probability that the Internal Control Department may misrepresent the audited financial statements from the internal audit even if carefully planned (Tian, 2013 ).

\subsection{The Importance of Studying}

The importance of the study stems from the following

1 - Accounting information systems are the cornerstone of any information system in commercial banks, which means that it is a database for investment decisions from stakeholders in commercial banks

2- The risks of accounting information systems must be controlled whether internal risks or external risks, so that these systems are credible and appropriate for decision making. The ease of penetration of accounting information systems leads to misrepresentation of accounting data which negatively affects the quality, to make decisions.

3 - The inputs of accounting information systems are the basis in the design of any program, whether an administrative or financial information or control, which means the need to pay attention to the accuracy of data and prevent the amendment of illegal, which reflects the credibility of accounting information and thus affect the effectiveness of internal control

4. Administrative control, accounting control and internal control are highly dependent on the inputs of the accounting systems. The correctness of the inputs of the accounting system is a reflection of the reduced risk of financial statements.

\subsection{Objectives of the Study}

The aim of this study is to focus on the risks of the input of accounting information systems and determine the extent of their impact on the nature of internal control departments represented by accounting control, administrative control and internal control. The study also aims at linking the risks of the inputs of the accounting information systems with the design of the internal control system in order to reduce the risks of internal control to the lowest level possible for the banks. Banks in general represent the largest risk-taking business enterprises, which mean that the risks of accounting information systems must be determined in order to arrive at a reasonable assurance that the statements in the financial statements are correct and accurately reflect the financial events in the banks. Therefore, this study aims at linking the accounting system and how to determine its risks and how to deal with the risks in case they occur. It also aims at how to invest the risks to obtain reliable financial data for decision making

\subsection{Previous Studies}

1- The study of Rosemary Kim 2017 " A framework for analytics and simulation of accounting information systems: A Petri net modeling primer.

Accountants have modeled and documented accounting information systems (AIS) through system flowcharts, which have also been used to study internal controls. However, when AIS are large, complex, and distributed, their system flowcharts are difficult to comprehend, challenging to use, and insufficient to support decision making in system design and implementation. In this primer we propose a set of requirements for modeling and documenting complex AIS that address those concerns. Since most other models such as SSAD, UML, and BPMN used to represent AIS are influenced by or can be reduced to Petri net models, we compare system flowcharts with Petri net representation of AIS. We evaluate systems flowcharts and Petri nets for their suitability in modeling AIS. We find that Petri nets are an attractive alternative due to their extensive capability to perform analytics and simulation. Analytics can be used to study structural and behavioral properties while simulations can help study run-time behavior of systems to evaluate computing capacity and system performance. We provide a detailed description and guidelines of how design analytics and implementation analytics can be achieved based on the Petri net framework. With this unified modeling strategy, we also describe how it can support the process of audit analytics. Petri nets are popular in computer science, engineering, manufacturing, supply chain management, and business process reengineering. We explore this viable method for rigorous study of AIS modeling and documentation. 
2-Al-Hosban, Hamdan 2015 "The Role of the Auditor in Planning and Reducing the Risk of IT Environment in commercial Jordanian Banks

The study aimed at showing the role of the internal auditor in dealing with the infrastructure of the IT environment and identifying the risks that can be faced by applying the computer, computer networks and their accessories to the nature of the work of the internal auditors. The questionnaire was used to obtain preliminary data for the study from a random sample on the internal auditors in the Jordanian commercial banks. The use of the statistical analysis program was used in analyzing the data such as arithmetic mean, standard deviation, frequencies and percentages. One of the most important results: The impact of the internal auditor on the infrastructure of the IT environment

3- Baker (2017) "Breakdowns in internal controls in bank trading information systems: The case of the fraud at Society General"

The purpose of this paper is to examine the failure to detect breakdowns in internal controls in a major bank's trading information systems related to a fraud perpetuated by a mid-level derivatives trader. Specifically, this paper examines the events uncovered at a large French bank, in January 2008. The paper addresses the question whether the apparent breakdowns in internal controls were caused by the fraudulent activities of a single trader acting alone or whether there may have been a certain level of acceptance of these activities on the part of the bank hierarchy as long as the trader was making a profit. The conclusion of the paper is that bank management may have overlooked overrides of internal controls over bank trading information systems during periods when risky trading practices resulted in profits, but that management quickly took action to correct the internal control overrides when the trading practices led to losses, thus re-emphasizing the crucial importance of tone at the top in the internal control environment. The paper will also address current and future potential research which may have prevented the fraud at Society General

4. Samukri (2015) "Influencing effective Internal Control System and Implementing financial accounting information system on the Quality of information system

The aim of this study was to show the effect of the efficiency of the internal control system and the impact of the implementation of the financial accounting information system on the quality of accounting information and its role in decision making. This study was based on the proposal of a model based on the integration of the requirements of the efficiency of the internal control system and the requirements of the financial accounting information systems in order to build a proposed model for the quality of financial accounting information and also to link them with the specific characteristics of accounting information in order to be valid for decision making by stakeholders. The most important results: The theoretical studies are the cornerstone in the construction of any theory expected, and the integration of internal control with the actual implementation of accounting systems information systems have a key role in obtaining accounting information has a predictive value and help to increase the reliability and credibility of that information. The most important recommendations are: the need for the participation of stakeholders in any organization in determining the characteristics of accounting information to be appropriate for them to make their decisions. The characteristics of accounting information are the basis when determining the use of accounting information, whether current or future investors

5- Al-Sharairi , AL-Hosban (2017) " Role of Internal Auditor in Dealing with Computer Networks Technology Applied Study in Islamic Banks in Jordan

The aim of the study was to identify Role of internal auditor in dealing with computer networks technology Applied study in Islamic banks in Jordan -. The objectives were to identify the role of the computer networks that are installed for the first time in addition to the role of the auditor in the physical components of computer networks and maintenance. The study community consists of internal auditors in Islamic banks or financial institutions, a total of 101 questionnaires were distributed and 89 questionnaires were retrieved for statistical analysis. A single sample test was used to test the hypotheses of the study. The arithmetic mean and the alpha test were used to find the internal consistency rate of the study sample. The most important results of the study: the presence of the impact of computer networks on the internal audit work environment both in the installation of the computer for the first time or provide the physical components of computer networks. The most important recommendations: The need to hold seminars and conferences using technology tools and their effects on the environment of internal auditing or external auditing or accounting environment in general.

\subsubsection{The Current Study Differs from Previous Studies}

The application of the study is based on the commercial banks in Jordan. The study tool is based on the design of 
a questionnaire prepared by the researcher, and the sample of the study is targeted at the internal auditors in the commercial banks.

1 - This study focuses on the inputs of the accounting system, while the previous studies focused on the accounting information system as a whole

2 - This study focuses on the risks of inputs to the accounting system on accounting control and administrative control and internal control, while the previous studies talk about the internal control system in general

3 - This study focuses on the impact of risk on internal controls through the inputs of the accounting system, while the previous studies focused on the impact of the risks of accounting information systems on the internal control system.

\section{The Theoretical Framework of the Study}

Internal control is more concerned with risk and risk assessment than ever before. The main reason for this is the possibility of changing the circumstances surrounding the company and the technological developments affecting the activities and the nature of the company's business. Risk is defined from the point of view of internal control as "the circumstances of uncertainty about the occurrence of things that have a significant impact on the objectives of the company, and these risks are measured by the repetition formula or the great probability of occurrence." The risk is certain to occur under the accounting information systems: the skills in the company do not affect them, and calculated probability of occurrence depending on a large number of observations. , And the regulatory system is weak. The risks of information technology, whether for information or the company's infrastructure, organizations assess the risks of modern technology based on these risks and their relationship to the company, such as: the application of performance, and the delivery of information systems, security, and the possibility of regression or erosion (Zeidi, 2012)

\subsection{Special Rules for Measuring Risk Assessment in an IT Environment: (Al-Hosban, 2009)}

1). Identify the risks that cause weakness and disruption of the Company's core activities and the resulting cash loss.

2). Determine the possibility of loss (appropriate loss of risk), including job and asset risks, preferably expressed in cash.

3). Determine the cash amount of the loss or weakness resulting from the occurrence of the threat (this is related to the second point).

4). Identification of the threat resulting from the possibility of recurrence of the event (the incidence of the threat), and expressed annually.

5). Determining the possibility of dealing with the main issues of risk: conditions of uncertainty. How to determine those circumstances and what to do if they are done.

6). Determine the cost efficiency either using the rate of return on investment or using cost and return.

\subsection{Steps to Assess the Risk of Input to Accounting Information Systems}

There are seven sequential steps to consider when determining an IT risk assessment as follows (Al-Hosban, 2009).

\section{1). Identification of information assets}

Important assets must be identified for each department. These important assets include: cutting off computers, software, systems, and related services, as well as technology related to them.

2). Compile and prioritize these assets

After completing the first step, the second step is to arrange the assets according to their importance, whether they are so sensitive that no work can be done without them or not. The second arrangement is suitable information that can be dispensed with for several days and not more than one week. It is the normal information that can be dispensed with and the work activities can be completed without it for a long time.

\section{3). Identification of risks}

Here, each risk circle determines whether these problems or threats are specific or not specific. Risks must be concrete and specific to one or more types of assets.

4). Prioritizing risks according to their importance

These give the Chambers an idea of where events need to be planned, and also work on sequential steps, making 
their management easier. So that sensitive risks are placed at the highest priority.

Develop a list containing risks Here, the members of the team assigned to identify the risks with explanations and details in support, depending on the knowledge they have about these risks.

5). Refer to risk according to sensitive assets (sensitive information)

In this step, the team prepares a list of the most sensitive assets (most at risk) prioritized in a separate part of the risk assessment report. This helps departments to propose appropriate solutions to those risks and implement plans to protect those assets.

6). Making appropriate recommendations to find solutions to those risks

2.3 The Information Technology Committee of the International Auditing Standards Committee (IFAC) in 2002 Also Notes that the Risks of the Electronic Work Environment Include: IFAC, ITC, 2002, P3

1). Risks of the electronic work environment infrastructure: inadequate security measures to prevent theft, illegal access or inappropriate disclosure of information, exposure to high temperature and natural disasters, inadequate procedures or poor safety of contingency plans and absence of support and support procedures

2). The risks of applications of the electronic work environment are the existence of problems in the application of the electronic work environment, the inadequacy of input controls, processing and directing designed on the applications of the electronic work environment, and insufficient procedures to secure software related to the security of electronic work environment information.

2.3.1 Some of the Risks Facing Computerized Information Systems can be summarized as Follows: (Hamed, 2009).

1). The unintentional introduction of an incorrect process or intentional introduction of data from a particular employee

2). Destruction of data, either intentionally or unintentionally, and unauthorized access to the accounting system

3). Weak physical control or human control of accounting information systems

4). Unauthorized access to the accounting system data or information available on it

5). Introduction of viruses on the accounting system or natural disasters

2.3.2 Risks of Accounting Information System Components (General Administration for Curriculum Development and Design, 2017)

1). Input risk: This is the risk of the initial introduction of accounting data, which is the modification or alteration of employee data intentionally or unintentionally, which negatively affects processing operations.

2). Risks of input processing: The risks in the memory of the IT tools used to process the accounting system data such as unauthorized entry, the participation of several people with the same passwords or the degree of similarity of large, and the interference of data entry through the server or computer networks.

3). Risks of the outputs of the accounting system: the risks related to the removal of financial statements from the computerized accounting system such as: illegal backups, the distribution of information to parties illegally, and the theft of certain data.

4). Environmental risks: natural disasters that may affect the accounting data through the disruption of computers or computer networks that distribute information to related persons, or the disruption of the system, which affects the policy of information security accounting.

\subsection{Accounting Information Systems}

System, information and information system concepts

2.4.1 The system can generally be defined as "a set of tangible and intangible elements (eg set of principles and procedures) that operate in a balanced network of communications that help flow information to ensure that the behavior that the system has to achieve is defined to achieve the goal or set of objectives "(Abdullah, 2012, p. 118)

2.4.2 The information system can be defined as "a process of operation and analysis to inform managers of the crisis to assist them in the implementation of the work and to make decisions within the organization, provided that such information is appropriate in terms of quality, timing and cost." (Abdullah, 2012, p. 112)

2.4.3 Information can be defined as: "Data processed and configured to reflect economic events and facts, which ensures that they increase the ability of their users to make appropriate decisions." 


\subsection{Characteristics of information systems}

It can be said that information systems have the following (Al-Hosban, 2013, p. 81)

1). The system shall be acceptable to the employees of the establishment and shall have a reasonable degree of persuasion for its importance and usefulness to them and to the establishment.

2). The system shall be designed to serve the functions and activities carried out by the establishment. The importance of this shall be indicated in the planning and control functions.

3). The system should be simple, and the flow of data from its sources is clear on a regular basis.

The system should be able to meet the needs of the decision-maker of the latest information and be linked to the internal control system.

\subsubsection{Risks of Input of Accounting Information Systems}

These risks relate to the first phase of the system, the stage of data entry into the computerized accounting system. These risks are as follows: (Al-Buhaisi, 2008, p. 35)

1). Intentional introduction of improper data by employees

2). Intentional introduction of improper data by employees

3). Unintentional destruction of data by staff

4). Intentional destruction of data by staff

\subsubsection{Problems of Accounting Information Systems in The Internal Control System}

Problems or risks related to accounting information systems under internal control can be summarized as follows (Llil, 2015, p 8)

1). The complexity of the control environment in the organization: This means the degree of acceptance of the management or the internal control system to deal with the risks of accounting information systems in addition to the degree of integrity of the administration in showing the risks of the information systems of senior management

2). Increasing the security risk of accounting information: This means the degree of reliance on the reliability and consistency of accounting information in the company, which depends on the stability of the organizational chart and the effectiveness of administrative control and internal control in the company, which means the security of accounting information of destruction or abuse

3). Expanding the applications of the use of information technology tools: The expansion of the use of technological applications means the need to develop internal control functions at the technical and technical level commensurate with the degree of technology applied in the company, and this is through the continuous development and qualification of employees with the applications of modern technology

\subsubsection{Effectiveness of Financial and Accounting Control and Internal Control}

First: the effectiveness of accounting and administrative control

Accounting is defined as a control that seeks to achieve a control over the financial and accounting regulations and instructions that aim to preserve the integrity of the assets of a particular establishment and to ensure the integrity of the financial statements of accounting errors. This means that the accounting control achieves general control and control of applications. This control is intended to ensure that the management's orders are implemented legally, that the financial operations are recorded historically and according to the accounting principles, the proper use of the assets of the establishment, and the conformity of the actual assets of the establishment with what is recorded in the books (Judges, 2008, p.

The effectiveness of financial and administrative control depends on the following (Moskov, 2007, p. 3012)

1). Track the course of financial operations and accounting operations from the original document until the end of that process in the financial statements and this ensures the correct application of accounting principles generally accepted

2). The efficiency of employees working in financial and accounting, where this factor is important to any system since the system of control in general depends on the efficiency of staff in terms of design, implementation and control

3). Separation of the conflicting functions between employees so that one employee is not allowed to take the registration and the migration and preparation of financial statements alone, which means there is more than one 
employee to prepare the financial process

4). Provide a system of physical protection of the assets of the establishment is a safe place and the use of electronic controls to maintain the assets of the establishment

Second, the effectiveness of administrative control

This control is based on the organizational plan to ensure the correct implementation of the administrative policies by the management of the establishment in order to achieve the productive efficiency of these policies. This control is done through statistical analysis of financial statements, the preparation of estimates and standard costs and the use of charts and performance reports. On the health and safety of financial and accounting controls (Judges, 2008, p. 48)

The effectiveness of administrative and financial control depends on the following factors: (Abu Delboh, 2017, p. 48)

1). provide a set of performance reports that aim to determine the negative or positive deviations between the actual and planned These measures are preventive control through the system of planning budgets and standard costs, and these reports are the basis for the success of administrative control

2). consistency of staff in the completion of their work so that the work of staff through regular coordination depends on the sequence of power lines based on the proper organizational structure, which determines the nature of the organizational relationship between staff and methods of applying the principle of management exception and the preparation of planning budgets (the method of informing the official when necessary)

3). Appropriate performance reports based on the feedback method that has a positive impact on the application of administrative policies by the staff and the efficiency of its application to achieve the objectives of the establishment, and aims to identify the persons responsible for any defect in the preparation, design or implementation of the organizational plan

Third: Effectiveness of the internal control system

This control is defined as based on the organizational plan and the accounting and financial control to ensure the effective use of the assets and assets of the establishment. The effectiveness of the internal control depends on the following factors (Al-Qudah, 2008, p. 50)

1).Effective financial and accounting control

2). Having a sound organizational plan that relies on all staff in terms of preparation, implementation and control

3). Integrity of the procedures for the protection of assets, whether material, human or electronic, to ensure the efficient and efficient use of these assets, according to the objective of the acquisition of the effective division of business among employees, which depends on the proper organizational structure in the distribution of functions and functions and responsibilities

\subsection{Hypotheses of the Study}

Based on the study problem, the study is based on the following hypotheses

1). There is no effect for the inputs of the accounting information systems on the administrative control in the Jordanian commercial banks

2). There is no effect for the input of the accounting information systems on the accounting control in the Jordanian commercial banks

3). There is no effect for the inputs of the accounting information systems on the internal control in the Jordanian commercial banks

\subsubsection{Justification for the Chosen of the Null Hypothesis}

It is known that the risks affect the internal control, and this effect is negative in terms of inputs, processes or outputs of the accounting system, which means the use of Alternative hypotheses do not serve as long as the result is known in advance, so the use of Null Hypothesis instead of alternative hypotheses to see the impact on sections Internal control to identify the real effects of the risks of system input

\subsubsection{Society and Sample of the Study}

The study population consists of internal auditors in Jordanian commercial banks. The study population was 218 internal auditors. The questionnaire was distributed to the sample using simple sample method. 170 questionnaires were distributed and 141 responses were retrieved. 


\section{Statistical Analysis}

\subsection{Introduction}

The following statistical methods were used: arithmetic mean, standard deviation, Kronbach alpha test, and one sample $t$ test.

The researcher also used a five-point scale (1-5) of the responses according to the five-dimensional Likert scale to determine the degree of approval of the study sample members on each paragraph of the study instrument ( for questionnaire). This measure helps to convert the responses to statistically measurable data, In order to determine the degree of importance of each of the paragraphs of the study when commenting on the mathematical averages of the variables in the study model, the statistical standard, which is based on dividing the computational medium, was used to three levels (high, medium, low) according to the following equation:

The length of the class $=$ (the upper limit of the alternative - the minimum of the alternative) $/$ the number of levels

The length of the class $=(5-1) / 3=4 / 3=1.33$ Thus the levels are as follows:

Low approval score: The arithmetical averages represent (1-2.33).

Medium approval: The arithmetical averages are (2.34-3.66).

High approval score: The arithmetical averages represent (3.67-5).

\subsection{Statistical Processing}

(SPSS), where the researcher entered the data into the computer and the use of several statistical methods to employ data to achieve the objectives of the study, and the following are the most important methods used:

1). Statistical methods descriptive: The use of the frequency distribution, percentages, and the mean and the standard deviation, in order to obtain general information on the characteristics, and composition of the sample study.

2). (Kronbach Alpha): in order to verify the extent of internal consistency of the study tool as one of the indicators of their stability.

\subsection{Test the Credibility and Stability of the Study}

The Kronbach alpha test was 75\%, which is higher than the minimum requirement of 70\%(Sekaran , 2010 ). This means that the degree of consistency of the sample responses is acceptable and reliable for generalizing the results and recommendations A total of 168 questionnaires were distributed to the internal auditors at the Jordanian commercial banks, of which 155 were received, and 14 were excluded due to their lack of validity for the statistical analysis. The total number of the study population is 213 internal auditors in commercial banks in Jordan.

\subsection{Characteristics of Study Sample Individuals}

Table 1. Characteristics of study sample by specialization

\begin{tabular}{lll}
\hline Title & Frequencies & Percentages \\
Accountant & 98 & $\% 70$ \\
Management & 31 & $\% 23$ \\
Economic/Finance & 12 & $\% 7$ \\
Total & 141 & 100 \\
Title & Frequencies & Percentages \\
Less than 6 years & 35 & $\% 25$ \\
6-less than 12 years & 77 & $54 \%$ \\
12 years and more & 29 & $21 \%$ \\
Total & 141 & 100 \\
Title & Frequencies & Percentages \\
College & 11 & $8 \%$ \\
University & 74 & $52 \%$ \\
Master & 30 & $21 \%$ \\
Ph.D. & 26 & $19 \%$ \\
Total & 141 & 100 \\
\hline
\end{tabular}


Note that the majority of the specialization of the study sample is from the accounting specialization. This percentage may be normal because the sample of the study is composed of internal auditors. It is normal to have a bachelor's degree in accounting specialization, especially since the banking sector requires specialization in the required job or job. Note from the above table that the majority of the sample of the sample with experience from 6 years to less than 12 years, and this is a positive indicator, as the subject of risk assessment needs to experience in the accounting information systems, it is noted that the rest of the ratios are close to each other in relation to the experiences of individuals The study sample. Note from the previous table that the vast majority of the sample of the study who hold the first degree and this is a positive indicator of the study and a good reflection on the results and recommendations of the study, also notes that there is a good proportion of postgraduate studies.

\subsection{Discuss the Statistical Results with the Hypotheses of the Study}

The first hypothesis: "There is no effect of the input of accounting information systems on administrative control in Jordanian commercial banks"

Table 2. The views of the study sample in the first hypothesis paragraphs

\begin{tabular}{|c|c|c|c|c|}
\hline Number & Title & Average & $\begin{array}{l}\text { Standards } \\
\text { deviation }\end{array}$ & Rank \\
\hline 1 & $\begin{array}{l}\text { The use of incorrect financial data in the accounting system has the effect of drawing up the } \\
\text { full strategy of the bank }\end{array}$ & 3.49 & 0.76 & 4 \\
\hline 2 & $\begin{array}{l}\text { The manipulation of the original documents of the accounting system has affected the } \\
\text { documentation of banking operations from several signatures to ensure the integrity of the } \\
\text { operations of the bank }\end{array}$ & 3.75 & 0.59 & 2 \\
\hline 3 & $\begin{array}{l}\text { The exclusion of some of the necessary data in the accounting system has an impact on the } \\
\text { process of forecasting the interim profit in the Bank }\end{array}$ & 2.76 & 0.52 & 5 \\
\hline 4 & $\begin{array}{l}\text { The duplication of accounting data in the accounting system has an impact on the efficiency } \\
\text { and effectiveness of administrative decisions in the bank }\end{array}$ & 4.19 & 0.86 & 1 \\
\hline 5 & $\begin{array}{l}\text { The creation of improper data in the accounting system has an effect on the effectiveness of } \\
\text { the distribution of powers and responsibilities in the bank }\end{array}$ & 3.24 & 0.78 & 3 \\
\hline Average & & 3.31 & & \\
\hline
\end{tabular}

It is noted from the above table that paragraph 4 represents the highest acceptance level with an average of 4.19. This indicates that the ratios of the strongly approved and the corresponding ratios are much higher than the non-approved ratios. This paragraph states that the risk of duplication of accounting data has an effect on the efficiency of administrative decisions in the bank. It indicates that the management of banks should work to monitor the numbers of transactions and their sequence and data to ensure that the repetition of inputs of accounting data, and this reflects positively on the effectiveness of administrative decisions, which reflects positively on administrative control. It is also noted that the risks of tampering with the original documents have an impact on ensuring the documentation of data related to the customers of the bank and thus lead to loss of customer rights. This indicates that the risks of tampering with the original documents have a negative impact on the nature of data authentication operations from several parties. And the lack of access to customer data is only through the legal statement. It also notes that the creation of sound data originally or non-existent has an impact on the determination of powers and responsibilities among the staff of the bank, which affects the quality of administrative control in banks, and This means that the data entry must be documented on the accounting system so as to ensure the transparency of the power lines in the bank. It is also noted that the average hypothesis is 3.31 which is higher than the accepted mean3. This means that the sample of the study confirms that there is a trace of the inputs of the accounting information systems to administrative control.

The second hypothesis "There is no effect of the inputs of the accounting information systems to the accounting control in the Jordanian commercial banks 
Table 3. The views of the study sample in the second hypotheses

\begin{tabular}{|c|c|c|c|c|}
\hline Number & Title & Average & $\begin{array}{l}\text { Standards } \\
\text { deviation }\end{array}$ & Rank \\
\hline 1 & There is an effect of incorrect data on the accuracy required to activate the internal control & 3.19 & 0.48 & 3 \\
\hline 2 & $\begin{array}{l}\text { The amendment or misrepresentation of the accounting system has an effect on the } \\
\text { classification of the financial operations of the Bank }\end{array}$ & 3.83 & 0.39 & 2 \\
\hline 3 & $\begin{array}{l}\text { The deletion of certain inputs prior to their use has an effect on the financial control and } \\
\text { consequently on the correctness of the financial statements of the bank }\end{array}$ & 4.38 & 0.78 & 1 \\
\hline 4 & $\begin{array}{l}\text { The introduction of data more than once in the accounting system has an impact on the } \\
\text { degree of integrity of data and information related to financial control }\end{array}$ & 2.16 & 0.78 & 5 \\
\hline 5 & $\begin{array}{l}\text { The deletion of certain data from the accounting system has an effect on the existence of } \\
\text { complete data on banking operations in the bank }\end{array}$ & 3.09 & 0.53 & 4 \\
\hline Average & & 3.34 & & \\
\hline
\end{tabular}

Note from the previous table that the sample members of the study confirms that the third paragraph has the highest impact with an average of 4.38 This paragraph is to hide any input on the accounting information system has an impact on the achievement of financial control and this therefore affects the validity and fairness of financial statements in the bank, Documenting the inputs of the accounting system from more than one side within the bank so that self-control can be achieved in the introduction of the accounting system data. It also leads to integration in the introduction of accounting system data and thus helps to reduce the risk of accounting system inputs. It is also noted that the second paragraph represents the second effect according to the rap of the sample of the study sample at an average of 3.83, and this paragraph is that any modification or change not authorized in the accounting system data has an impact on the manual of accounts and thus affect the process of classifying elements of the financial statements and thus affect the credibility of lists This means that there is physical, human and electronic protection of accounting data, with precise policies to protect the accounting system data from unauthorized modification or modification. It is also noted that the first paragraph represents the third degree of acceptance according to the opinion of the sample members of the study. This paragraph is that there is an impact to the introduction of accounting data on the correct efficiency and effectiveness of the internal control system, which means the need to reduce the risk of introducing false data on the accounting system through the use of IT tools In the bank that have an effect on preventing illegal penetration of the accounting system data both inside and outside the bank. The risk of incorrect entry on the accounting system data can also be reduced by documenting the accounting data manually and electronically. This study shows that the study sample members confirm that there is a significant impact of the accounting system's input on accounting control.

The third hypothesis: "There is no effect of the inputs of the accounting information systems on internal control in the Jordanian commercial banks"

Table 4. The views of the study sample in the paragraphs of the third hypothesis

\begin{tabular}{|c|c|c|c|c|}
\hline Number & Title & Average & $\begin{array}{l}\text { Standards } \\
\text { deviation }\end{array}$ & Rank \\
\hline 1 & $\begin{array}{l}\text { Modification or modification of input data to the accounting system has an effect on the } \\
\text { early detection of errors in the implementation of the pre-planned regulatory plan }\end{array}$ & 3.76 & 0.48 & 3 \\
\hline 2 & $\begin{array}{l}\text { The development of a set of data within a set of processes in the accounting system affects } \\
\text { the determination of correct deviations in the performance of the operations of the bank }\end{array}$ & 3.19 & 0.95 & 4 \\
\hline 3 & $\begin{array}{l}\text { The manipulation of the original documents after their adoption in the accounting system } \\
\text { has an impact on the effectiveness of achieving control over the optimal use of the bank's } \\
\text { assets }\end{array}$ & 4.16 & 0.59 & 1 \\
\hline 4 & $\begin{array}{l}\text { The unauthorized use of the accounting system has an impact on the means of achieving } \\
\text { effective control to prevent the misuse of the bank's assets }\end{array}$ & 3.89 & 0.34 & 2 \\
\hline Average & & & & \\
\hline
\end{tabular}

It is noted from the previous table that the third paragraph represents the highest effect with an average of 4.16. This paragraph is that the manipulation of the original documents after their adoption in the accounting system has an effect on the effectiveness of achieving control over the optimal use of the bank's assets. This means that 
there is an internal review of the accounting system data By modifying them from the same employee, but there is more than one party to enter, review or modify them, and thus can reduce the risk of introducing false data on the accounting system and thus the possibility of achieving the overall goal of internal control of the optimal use of D Bank. It is also noted that the fourth paragraph represents the second degree of acceptance with an average of 3.89, and this paragraph is that the unauthorized use of the accounting system has an impact on the means to achieve effective control to prevent the misuse of the assets of the bank, and this is aware of the need to activate internal control methods within the accounting system in terms of changing passwords To prevent entry to the accounting system from outside the bank, and to document all processes and turnover of work among the working staff. It is also noted that the average assumption is 3.75 which is higher than the satisfactory mean 3 this indicates that the risk of input to the accounting system affects the internal controls in the bank.

\section{Conclusions and Recommendations}

\subsection{First Results}

The study found the following results

1. The impact of the risks of the inputs of the accounting information systems on administrative control is as follows:

- The existence of duplication of the introduction of accounting data have an impact on the efficiency of administrative decisions, which means that banks must document the accounting system data from more than one control

- The manipulation of inputs of the accounting system has affected the documentation of the operations carried out by the bank to customers, and thus may lead to the loss of their rights.

- The creation of sound accounting data affects the distribution of competencies and competencies among employees. This means that it is difficult to design a sound organizational structure in the bank and this is reflected in the nature of the operations in the bank.

\section{2 - The impact of the risk of the inputs of the accounting system on accounting control is as follows}

- The deletion of some inputs before their use has an impact on the financial control and thus the validity of the financial statements of the bank, which means the need to integrate the introduction of accounting system data so that it can activate the prevention of the introduction of incorrect data on the accounting system

- The deletion of certain data from the accounting system has affected the existence of complete data on banking operations in the bank, which means the need to review the introduction of accounting data on the accounting system after the initial entry by another person to achieve self-control

3 - The impact of the risk of the inputs of the accounting system on internal control procedures is as follows

- The manipulation of original documents after their adoption in the accounting system has an impact on the effectiveness of achieving control over the optimal use of the assets of the bank. This means separating the terms of reference between the employees who receive the original documents and the employees who enter the original documents input on the computerized accounting system.

- The unauthorized use of the accounting system has an effect on the means of achieving effective control to prevent the misuse of the bank's assets

\subsection{Second, Recommendations}

Based on the results of the study, the most important recommendations are the following:

1 - The need to introduce all the components of the original documents on the computerized accounting system for the purpose of documenting these data to ensure the operations carried out by the bank and the implementation of profit forecasts and others

2 - The need to document all inputs to the computerized accounting system in order to prevent duplication in the introduction of accounting data and thus obtain the correct financial statements

3 - The need to review the introduction of data more than once in the accounting system because of the impact on the degree of integrity of data and information related to financial control

4 - The need to rehabilitate the internal auditors in the banks in how to deal with the risks of input of accounting information systems through training courses and scientific qualification.

5 - Holding scientific seminars and conferences that will be specialized in dealing with the risks of accounting information systems in general, and dealing with the risks of inputs to the accounting system in particular 


\section{References}

Abdullah, K. A. (2012). Audit and Control in Banks. Dar Wael Publishing and Distribution, Amman, Jordan.

Al-Buhaisi, E. (2008). The Risks of Electronic Information Systems. Journal of the Islamic University, 6, 35.

Al-Dalahmah, S. M. (2008). The Basics of Accounting Information Systems. Al Warraq Publishing \& Distribution, Amman, Jordan.

Al-hosban, A. A. (2009). Internal Audit and Control in the IT Environment. Dar Al-Hamed Publishing, Amman, Jordan.

Al-Hosban, A. A. (2013). Accounting Information Systems. Dar Al Yazuri: Amman, Jordan.

Alhosban, A. A., \& Mohammed, A. (2017). Role of Internal Auditor in Dealing with Computer Networks Technology - Applied Study in Islamic Banks in Jordan. International Business Research, 10(6).

Al-Hosban, A., \& Mohammed, H. (2015). The Role of the Auditor in Planning and Reducing the Risk of IT Environment in Commercial Jordanian Banks. International Journal of Economics and Finance, 7(11).

Al-Qudah, G. M. (2008). Effect of Accounting Information Systems on the Effectiveness of Internal Control in Commercial Banks in Jordan, Master Thesis. Al-Bayt University, Mafraq, Jordan.

Baker, R. (2017). Breakdowns in internal controls in bank trading information systems: The case of the fraud at Society General. International Journal of Accounting Information System, 26.

Bo, H. A. (2015). The Role of the Accounting Information System in the Effectiveness of Internal Control in Petroleum Companies in Algeria, Master Thesis, University of QasidiMarbah, Ouargla, Algeria, Algeria.

General Administration for Curriculum Development and Design. (2017). Auditing and Auditing. General Organization for Technical Education and Training, Riyadh, Saudi Arabia.

Hamid, A. N. (2009). The Risks of Accounting Information Systems in the Jordanian Industrial Sector. Master Thesis, Yarmouk University, Irbid, Jordan.

IFAC. (2002), ITC, Annual Report IFAC Global Gate away.

Lili, Z. (2015). Innovation Research of internal Accounting Information System under network System, International Conference on Education Technology, Management and Humanities Science (ETMHS 2015).

Moskoff, S. (2007). Accounting Information Systems translated by Kamal Al-Din Saeed, Dar Al-Marikh Publishing, Riyadh, Saudi Arabia.

Roomney. (2015). Accounting Information System (13th ed.). USA: Pearson

Rosemary, K. (2017) “A framework for analytics and simulation of accounting information systems: A Petri net modeling primer. International Journal of Accounting Information System, 27.

Samukri. (2015). Influencing effective Internal Control System and implementation of financial accounting information system on the Quality of information system research. Journal of Finance and Accounting, $6(11)$.

Tian, G. (2013). The Impact of ineffective Internal Control on The Value Relevance of Accounting Information. Asia-Pacific Journal of Accounting \& Economics, 20(3).

Uma, S. (2010). Research methods for business: A skill-building approach. John Wiley \& Sons.

Zeidi, N. T. (2012). Measuring the Effect of Risk Factors on Audit Reports: An Empirical Study. Al-Muthanna Journal of Administrative Sciences, 2(4), 58-92.

\section{Copyrights}

Copyright for this article is retained by the author(s), with first publication rights granted to the journal.

This is an open-access article distributed under the terms and conditions of the Creative Commons Attribution license (http://creativecommons.org/licenses/by/4.0/). 